\title{
Isolation Optimization Method on the Coupler
}

\author{
Yudi Barnadi*, M. Rozahi Istambul, Ajeng Mayang K S, Savitri galih
}

Widyatama University, Malaysia, Indonesia

Copyright $\bigcirc 2019$ by authors, all rights reserved. Authors agree that this article remains permanently open access under the terms of the Creative Commons Attribution License 4.0 International License

\begin{abstract}
In this type of radar pulses only have one antenna that is used to transmit and receive signals, it requires a duplexer that will function as a separator for both signals, this duplexer will isolate the transmitted signal and the received signal. The main component of the duplexer that plays a role in the regulation of isolation is the Coupler which is abbreviated as coupler. The performance of the Coupler can be seen from the characteristics of the parameters it has, namely: Isolation Characteristics, Insertion Loss, Return Loss, and Power Coupling. In this study, changes in the dimensions of the Coupler, changes in this size will affect the value of the isolation. If the isolation value gets smaller, the duplexer performance will be better. Coupler in this study is applied in the form of microstrip and substrate used FR-4 with a dielectric constant of 4.6, $1.3 \mathrm{~mm}$ thick and $3 \mathrm{GHz}$ operating frequency. To do this work is done with the 2014 CST simulation software, from the results of simulation experiments obtained the isolation value of $-67.786 \mathrm{~dB}$.
\end{abstract}

Keyword Coupler, Duplexer, Isolation, Pulse Radar

\section{Introduction}

The Coupler is a four-terminal passive device that has 4 symmetrical linear arms to produce an output signal that is different in phase 90 [1]. An ideal Coupler will have a matching condition, not having losses (lossless) and reciprocity, its performance is determined by: return loss, insertion loss, coupling factor and isolation. Couplers are part of the Duplexer, and this duplexer is one part of the pulse radar. Pulse radar only has one antenna, the antenna used to transmit and receive signals is the same antenna. In [2] the duplexer has the ability to separate the transmitted signal and the received signal.

The conventional Coupler generally has a fairly large dimension and has an isolation value of $<-20 \mathrm{~dB}$ at high frequencies with this isolation characteristic cannot be used because of the many signals with different phase angles [3]. The purpose of this study is to obtain a better Coupler isolation value which is smaller than $<-55 \mathrm{~dB}$.
In other studies a parallel type of microstrip coupler has been widely used because it has a simple and it is easily to made shape [3]. The weakness is the lack of good isolation and directivity values

In [4] the technique is done by adding the apperture ground plane, this method can improve the isolation of the conventional coupler, but because of the difficulty of fabrication, and this technique cannot be done in the form of MMC. -junction Coupler and it produces an isolation value of $-55 \mathrm{~dB}$. In [5] used two diode capacitance variables in the circuit that are useful as tuning to obtain the desired working frequency, from the simulation results obtained an improvement of isolation of - $52 \mathrm{~dB}$ [6]. In [3] size reduction, weight but has a higher level of integration and lower power consumption as in [7] in the form of Monolithic Microwave Integrated-Circuit (MMIC) and thin-film multichip module technology (MCM-D ) [8] integrated into microstrip [6] and T/ R swiching circuit [9]. For this purpose a design is needed that is integrated between active and passive components. But the method of integrating the above components produces a low isolation below $-20 \mathrm{~dB}$.

In [10] a coupler is used as a separator between the sender and the receiver, the antenna that sends and receives signals that have a different polarization. Modification process of the coupler dimensions at $\mathrm{T}$ junctions with physical parameters W50 $\Omega: 2,952 \mathrm{~mm}, \mathrm{~L} 50 \Omega: 15.2 \mathrm{~mm}$ and W35, $35 \Omega: 5,14 \mathrm{~mm}, \mathrm{~L} 35,35 \Omega: 15.2 \mathrm{~mm}$ from the simulation results obtained isolation values $-31,185 \mathrm{~dB}$. In [12] a patch-coupled directional coupled patch which has an ellip-shaped patch with an arm length of $22.5 \mathrm{~mm}$, is used Ro Rogers substrate 4003C 3.38 dielectric constant at a working frequency of $2 \mathrm{GHz}$ obtained an isolation value of $-45 \mathrm{~dB}$.

In this study, FR-4 is used because it is easily obtained in the market, to obtain best is the result of the optimization of the transmission coupler channel by modifying the length and width of the series arm $(\mathrm{Zo}=50 \Omega)$, the length and width of the series arm $(Z o=35.35 \Omega)$, the length and width of the parallel arm $(\mathrm{Zo}=50 \Omega)$ to do the optimization. With CST simulation software 2014. Simulation results obtained isolation values of $-67,786 \mathrm{db}$. 


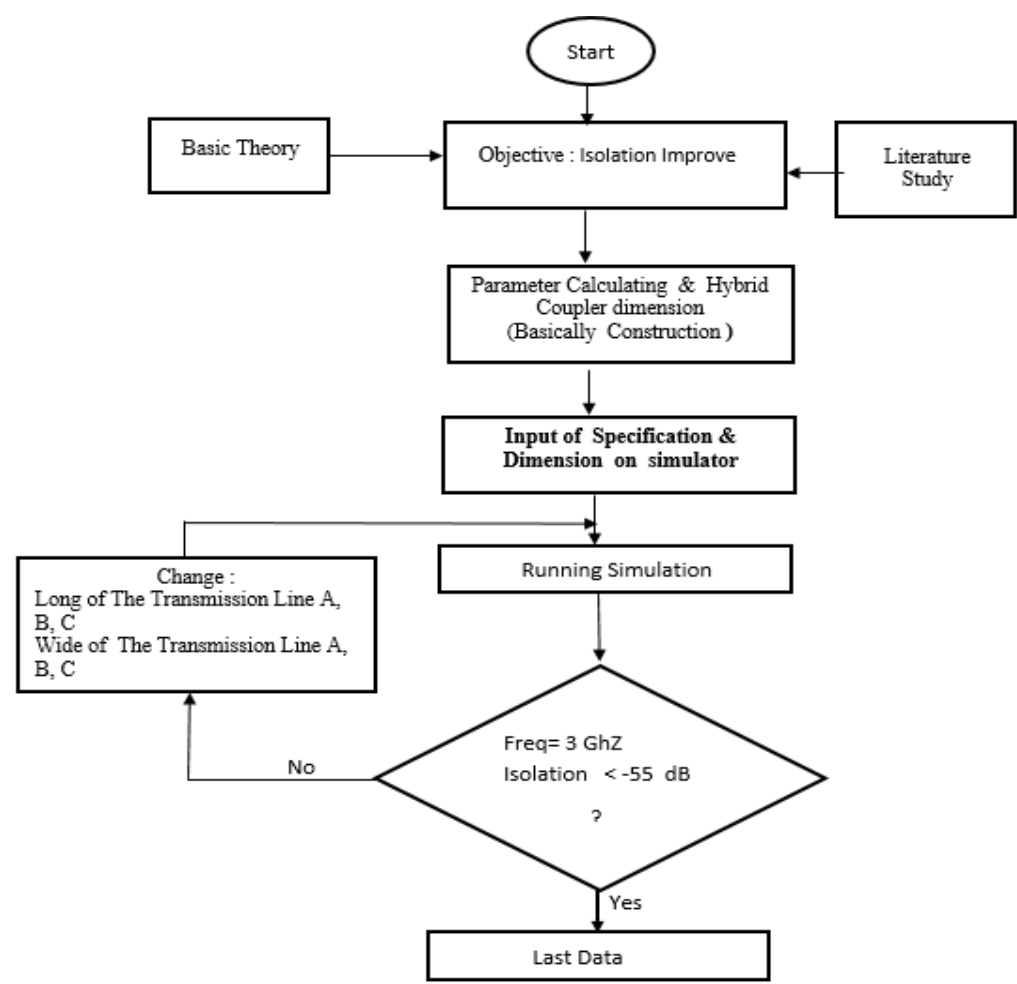

Figure 1. Flow chart optimization of the Coupler

\section{Research Methodology}

The design at the Coupler is performed to obtain a good performance, the coupler works at $3 \mathrm{GHz}$ operating frequency and is implemented on the $\mathrm{S}$ band frequency.

There are several steps to design this Microstrip Coupler which is to determine the specifications of the coupler, determine the substrate to be used, the design of the coupler geometry is designed and then calculate the microstrip physical parameters designed using the formula for microstrip design. Then simulated using Computer Simulation Technology (CST) 2014 Software.

\subsection{Determine the Specifications of the Coupler}

The initial step in the design is to carry out the specifications of the coupler that will design. The design of the coupler is to get isolation characteristics that are better than $-55 \mathrm{~dB}$, operating frequency $3 \mathrm{GHz}$. Coupler for this design has the following specifications:

Frequency: $3 \mathrm{GHz}$

Material: FR-4 (Efoxy)

Permitivitas $\left(\boldsymbol{\varepsilon}_{\mathrm{r}}\right): 4,6$

Thickness (h): 1, $3 \mathrm{~mm}$

Copper thicknes: $0.035 \mathrm{~mm}$

Light speed (c): $3 \times 10^{8} \mathrm{~mm} / \mathrm{s}$

$\mathrm{Z}_{0}: 50 \mathrm{ohm} Z o / \sqrt{2}: 35,35 \mathrm{ohm}$

Vswr: $<1,5$

Isolation: $<-55 \mathrm{~dB}$

This Coupler is designed at 50 ohms impedance.
Therefore, the quarter wavelength portion of the device has an impedance of $50 \mathrm{ohms}$ and $35.35 \mathrm{ohms}$. The coupler will be made from microstrip on FR4 (Epoxy) substrate. For the first design, the length and width of the transmission line is calculated using the formula in [3]

\section{A. Calculation}

In this research studies, the substrate used type FR 4, determines the wavelength $(\lambda \mathrm{g})$ which propagates on the material used. The wavelength propagating in the material has the following equation $[5,16]$ :

$$
\begin{gathered}
\lambda \mathrm{g}=\frac{\mathrm{c}}{\mathrm{f} \times \sqrt{\varepsilon \mathrm{r}}} \\
\lambda \mathrm{g}=\frac{3 \times 10^{8}}{\left(3 \times 10^{9}\right) \times \sqrt{4,6}}=0,04612 \mathrm{~m}=46,63 \mathrm{~mm}
\end{gathered}
$$

From the calculation, the wavelength $(\lambda \mathrm{g})$ obtained is $46.63 \mathrm{~mm}$

$\lambda g=\frac{46,12}{4}=11,66 \mathrm{~mm}$, then the long $\mathrm{AP}=\mathrm{BP}=\mathrm{CP}$ $=11,66 \mathrm{~mm}$

- To determine the width can be calculated [5] :

$$
\frac{W}{d}=\frac{e^{a}}{e^{2 a}-2}
$$

where $\mathrm{Zo}$ is $50 \Omega$ :

$$
a=\frac{z_{0}}{60} \sqrt{\frac{\varepsilon_{r}+1}{2}}+\frac{\varepsilon_{r}-1}{\varepsilon_{r}+1}\left(0.23+\frac{0.11}{\varepsilon_{r}}\right)
$$

then: 


$$
\begin{aligned}
& a=\frac{50}{60} \sqrt{\frac{4,6+1}{2}}+\frac{4,6-1}{4,6+1}\left(0.23+\frac{0.11}{4,6}\right) \\
& \text { - } \quad a=1,56 \\
& \frac{W}{d}=\frac{8_{e} a}{e^{2 a}-2} \\
& \frac{W}{d}=\frac{8 e^{1,61}}{e^{2.1,61}-2} \\
& \frac{W}{d}=1,845, \mathrm{~d}=1,30 \mathrm{~mm} \text {, } \\
& w=1,845 x 1,30=2,398 \mathrm{~mm} \\
& A L=B L=2,398 \mathrm{~mm} \\
& \text { If } \mathrm{Z}_{0}=35,35 \Omega \\
& \text { - } \quad a=\frac{35,35}{60} \sqrt{\frac{4,6+1}{2}}+\frac{4,6-1}{4,6+1}\left(0.23+\frac{0.11}{4,6}\right)=1,149 \\
& \text { - } \quad \frac{W}{d}=\frac{8 e^{1,149}}{e^{2.1,149}-2}=3,173 \\
& \text { - } \quad w=3,173 \times 1,3=4,125 \mathrm{~mm}
\end{aligned}
$$

Then $\mathrm{CL}=4,125 \mathrm{~mm}$, the value of transmission line AP $=\mathrm{BP}=\mathrm{CP}=11,66 \mathrm{~mm}, \mathrm{AL}=\mathrm{BL}=2,398 \mathrm{~mm}$ dan $\mathrm{CL}=$ $4,125 \mathrm{~mm}$

Tabel 1. The size of the transmission line from the calculation results

\begin{tabular}{|c|c|}
\hline $\begin{array}{c}\text { Parameter } \\
\text { (Variable) }\end{array}$ & $\begin{array}{c}\text { The length of } \\
\text { transmission line } \\
(\mathrm{mm})\end{array}$ \\
\hline AP & 11,66 \\
\hline BP & 11,66 \\
\hline CP & 11,66 \\
\hline AL & 2,398 \\
\hline BL & 2,398 \\
\hline CL & 4,125 \\
\hline
\end{tabular}

From table 1. length of transmission line A $(A P)=11.66$ $\mathrm{mm}$, length of transmission line $\mathrm{B}(\mathrm{BP})=11.66 \mathrm{~mm}$, length of transmission line $\mathrm{C}(\mathrm{CP})=11.66 \mathrm{~mm}$, width of transmission line $\mathrm{A}(\mathrm{AL})=2,398 \mathrm{~mm}$, width of transmission line $(B L)=2,398 \mathrm{~mm}$, width of transmission line $\mathrm{C}(\mathrm{CL})=4,125$ $\mathrm{mm}$.

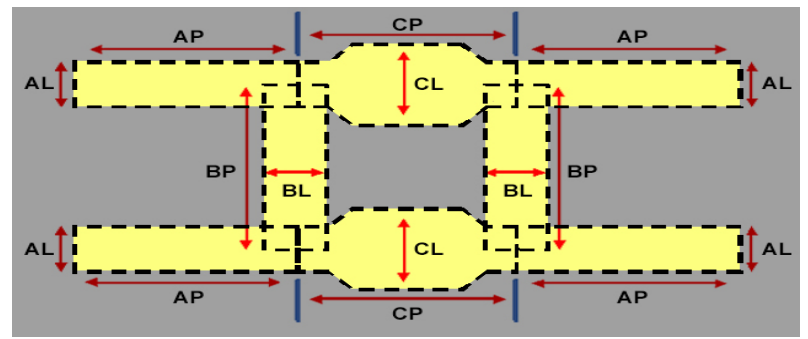

Figure 2. Design of the Coupler

Where are the abbreviations as follows: $\mathrm{AP}=$ Length of transmission line $\mathrm{A}(\mathrm{mm})$ $\mathrm{BP}=$ Length of transmission line $\mathrm{B}(\mathrm{mm})$
$\mathrm{CP}=$ Length of transmission line $\mathrm{C}(\mathrm{mm})$

$\mathrm{AL}=$ width of the transmission line $\mathrm{A}(\mathrm{mm})$

$\mathrm{BL}=$ width of the transmission line $\mathrm{B}(\mathrm{mm})$

$\mathrm{CL}=$ width of the transmission line $\mathrm{C}(\mathrm{mm})$

Figure 3. Shows the layout of the Coupler construction obtained from the simulation.

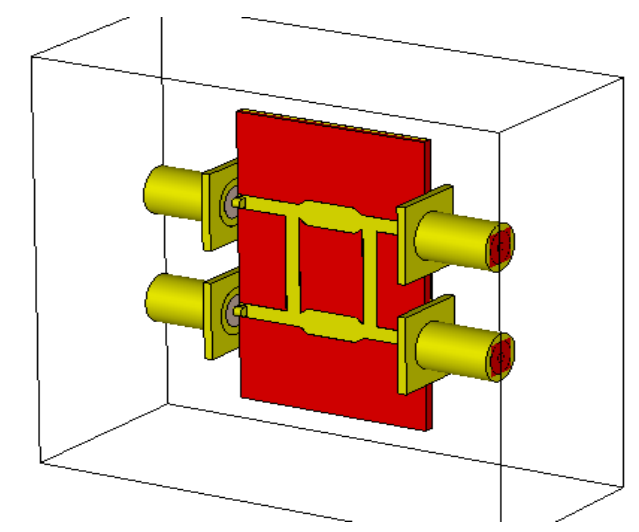

Figure 3. Construction of the Coupler

\section{Research Method}

This research begin with a calculation of the dimensions of the conventional BLC formula. This initial design calculation will be examined in the simulation. Modification on BLC dimensions is conducted as a way to obtain optimum results in simulation, then the optimum design will be fabricated. The BLC is designed using $90^{\circ}$ Hybrid Coupler, with a resonant frequency at $3 \mathrm{GHz}$.

a. Calculation of the Length of the transmission line

The length (L) of the coupler usually equal to a quarter of wavelength which propagates in material as follow [10, 11]:

$$
\begin{gathered}
\lambda \mathrm{g}=\frac{\mathrm{c}}{\mathrm{f} \times \sqrt{\varepsilon \mathrm{r}}} \\
\lambda \mathrm{d}=\frac{\lambda \mathrm{g}}{4}
\end{gathered}
$$

where $\mathrm{f}$ is operating frequency of the coupler, and $\mathrm{\varepsilon r}$ is dielectric constant of the substrate.

b. Calculation of the Width transmission line

$$
\frac{W}{d}=\frac{8 e^{a}}{e^{2 a}-2}
$$

Where $Z_{\mathrm{o}}$ is $50 \Omega$ and $35,35 \Omega$

$$
a=\frac{Z_{0}}{60} \sqrt{\frac{\varepsilon_{r}+1}{2}}+\frac{\varepsilon_{r}-1}{\varepsilon_{r}+1}\left(0.23+\frac{0.11}{\varepsilon_{r}}\right)
$$

From calculation of the above formulas, there are obtained the dimension of $\mathrm{AP}=\mathrm{BP}=\mathrm{CP}=11.66 \mathrm{~mm}$, $\mathrm{AL}=\mathrm{BL}=2.398 \mathrm{~mm}, \mathrm{CL}=4.125 \mathrm{~mm}$ 


\section{c. Procedure:}

The modification of the coupler determines the effect changes in the length and width of the transmission line A, $\mathrm{B}$ and $\mathrm{C}$ branchline coupler to the isolation value.

1.The length of the transmission line A (AP-1) and B (BP-1) is reduced, but the length of the transmission line $\mathrm{C}$ (CP), and the width of the transmission line $\mathrm{Al}, \mathrm{BL}$ and $\mathrm{CL}$ does not change (the same as the value of the calculation result ), this can be seen in table 2 .

The length of the transmission line A (AP-1) is reduced from $11.66 \mathrm{~mm}, 11.55 \mathrm{~mm}, 11.50 \mathrm{~mm}, 10.50 \mathrm{~mm}$ and last $10.35 \mathrm{~mm}$, but the length of the transmission line BP, CP, and the width of the transmission line $\mathrm{Al}, \mathrm{BL}$ and $\mathrm{CL}$ does not change (the same as the value of the results of the calculation), this can be seen in Table 2 .

Table 2. Reduction in length of transmission line A

\begin{tabular}{|l|l|l|l|l|l|l|l|l|}
\hline No & $\begin{array}{l}\text { AP-1 } \\
(\mathrm{mm})\end{array}$ & $\begin{array}{l}\text { BP } \\
(\mathrm{mm})\end{array}$ & $\begin{array}{l}\mathrm{CP} \\
(\mathrm{mm}\end{array}$ & $\begin{array}{l}\text { AL } \\
(\mathrm{mm})\end{array}$ & $\begin{array}{l}\text { BL } \\
(\mathrm{mm})\end{array}$ & $\begin{array}{l}\mathrm{CL} \\
(\mathrm{mm})\end{array}$ & $\begin{array}{l}\text { Freq } \\
(\mathrm{GHz})\end{array}$ & $\begin{array}{l}\text { S1.4 } \\
(\mathrm{dB})\end{array}$ \\
\hline 1 & 11.66 & 11.66 & 11.66 & 2.398 & 2.398 & 4.125 & 2.814 & -34.36 \\
\hline 2 & 11.55 & 11.66 & 11.66 & 2.398 & 2.398 & 4.125 & 2.816 & -34.16 \\
\hline 3 & 10,50 & 11.66 & 11.66 & 2.398 & 2.398 & 4.125 & 2.819 & -30.03 \\
\hline 4 & 10,45 & 11.66 & 11.66 & 2.398 & 2.398 & 4.125 & 2.820 & -30.04 \\
\hline 5 & 10,40 & 11.66 & 11.66 & 2.398 & 2.398 & 4.125 & 2.823 & -30.01 \\
\hline 6 & 10,38 & 11.66 & 11.66 & 2.398 & 2.398 & 4.125 & 2.824 & -30.01 \\
\hline 7 & 10,37 & 11.66 & 11.66 & 2.398 & 2.398 & 4.125 & 2.824 & -30.01 \\
\hline 8 & 10,36 & 11.66 & 11.66 & 2.398 & 2.398 & 4.125 & 2.824 & -29.99 \\
\hline 9 & 10,35 & 11.66 & 11.66 & 2.398 & 2.398 & 4.125 & 2.824 & -29.99 \\
\hline
\end{tabular}

The length of the transmission line A (AP-1) and B (BP-1) is reduced from $11.56 \mathrm{~mm}, 11.50 \mathrm{~mm}, 10.50 \mathrm{~mm}$, $10.47 \mathrm{~mm}$ and last $10.36 \mathrm{~mm}$, but the length of the transmission line $\mathrm{CP}$, and the width of the transmission line $\mathrm{Al}, \mathrm{BL}$ and $\mathrm{CL}$ does not change (the same as the value of the results of the calculation), this can be seen in Table 3 . Table 3. Reduction in length of transmission line A

\begin{tabular}{|l|l|l|l|l|l|l|l|l|}
\hline No & $\begin{array}{l}\text { AP-1 } \\
(\mathrm{mm})\end{array}$ & $\begin{array}{l}\text { BP-1 } \\
(\mathrm{mm})\end{array}$ & $\begin{array}{l}\mathrm{CP} \\
(\mathrm{mm}\end{array}$ & $\begin{array}{l}\text { AL } \\
(\mathrm{mm})\end{array}$ & $\begin{array}{l}\text { BL } \\
(\mathrm{mm})\end{array}$ & $\begin{array}{l}\mathrm{CL} \\
(\mathrm{mm})\end{array}$ & $\begin{array}{l}\text { Freq } \\
(\mathrm{GHz})\end{array}$ & $\begin{array}{l}\mathrm{S} 1.4 \\
(\mathrm{~dB})\end{array}$ \\
\hline 1 & 11.66 & 11.56 & 11.66 & 2.398 & 2.398 & 4.125 & 2.814 & -34.36 \\
\hline 2 & 11.55 & 11.50 & 11.66 & 2.398 & 2.398 & 4.125 & 2.816 & -34.16 \\
\hline 3 & 10,50 & 10,50 & 11.66 & 2.398 & 2.398 & 4.125 & 2.819 & -30.03 \\
\hline 4 & 10,45 & 10.47 & 11.66 & 2.398 & 2.398 & 4.125 & 2.820 & -30.04 \\
\hline 5 & 10,40 & 10.46 & 11.66 & 2.398 & 2.398 & 4.125 & 2.823 & -30.01 \\
\hline 6 & 10,38 & 10.40 & 11.66 & 2.398 & 2.398 & 4.125 & 2.824 & -30.01 \\
\hline 7 & 10,37 & 10.38 & 11.66 & 2.398 & 2.398 & 4.125 & 2.824 & -30.01 \\
\hline 8 & 10,36 & 10.37 & 11.66 & 2.398 & 2.398 & 4.125 & 2.824 & -29.99 \\
\hline 9 & 10,35 & 10.36 & 11.66 & 2.398 & 2.398 & 4.125 & 2.824 & -29.99 \\
\hline
\end{tabular}

The length of the transmission line A (AP-2), B (BP-2), $\mathrm{C}(\mathrm{CP}-2)$ are reduced, but the width of the transmission line A (AL-1), B (BL-1) and C ( CL-1) increases from 4.037 $\mathrm{mm}, 4.200 \mathrm{~mm}, 4.800 \mathrm{~mm}, 5.000 \mathrm{~mm}, 5.020$ and last 5.067 $\mathrm{mm}$. this can be seen in table 4 .

Table 4. The Width addition of the transmission line $\mathrm{C}$

\begin{tabular}{|l|l|l|l|l|l|l|l|l|}
\hline No & $\begin{array}{l}\text { AP-1 } \\
(\mathrm{mm})\end{array}$ & $\begin{array}{l}\text { BP-1 } \\
(\mathrm{mm})\end{array}$ & $\begin{array}{l}\text { CP-1 } \\
(\mathrm{mm}\end{array}$ & $\begin{array}{l}\text { AL-1 } \\
(\mathrm{mm})\end{array}$ & $\begin{array}{l}\text { BL-1 } \\
(\mathrm{mm})\end{array}$ & $\begin{array}{l}\text { CL-1 } \\
(\mathrm{mm})\end{array}$ & $\begin{array}{l}\text { Freq } \\
(\mathrm{GHz})\end{array}$ & $\begin{array}{l}\text { S1.4 } \\
(\mathrm{dB})\end{array}$ \\
\hline 1 & 11.55 & 11.56 & 11.53 & 2.38 & 2.38 & 4.037 & 2.835 & -31.84 \\
\hline 2 & 11.50 & 11.50 & 11.48 & 2.48 & 2.40 & 4.200 & 2.865 & -27.48 \\
\hline 3 & 10,50 & 10,50 & 11.35 & 2.56 & 2.56 & 4.800 & 2.819 & -35.08 \\
\hline 4 & 10,45 & 10.47 & 10.30 & 2.68 & 2.76 & 5.000 & 2.980 & -36.83 \\
\hline 5 & 10,40 & 10.46 & 10.28 & 2.70 & 2.80 & 5.020 & 2.980 & -38.07 \\
\hline 6 & 10,38 & 10.40 & 10.26 & 2.75 & 2.83 & 5.040 & 2.993 & -48.22 \\
\hline 7 & 10,37 & 10.38 & 10.25 & 2.76 & 2.84 & 5.050 & 3.000 & -64.29 \\
\hline 8 & 10,36 & 10.37 & 10.24 & 2.77 & 2.85 & 5.060 & 3.000 & -66.24 \\
\hline 9 & 10,35 & 10.36 & 10.23 & 2.78 & 2.86 & 5.067 & 3.000 & -67.79 \\
\hline
\end{tabular}

And it can be seen in point number 7, the frequency value is at the $3 \mathrm{GHz}$ position optimal dimension with the best isolation value obtained are when AP-1 $=10.35 \mathrm{~mm}$, $\mathrm{BP}-1=10.36 \mathrm{~mm}, \mathrm{CP}-1=10.23 \mathrm{~mm}, \mathrm{AL}-1=2.78 \mathrm{~mm}$, $\mathrm{BL}-1=2.86 \mathrm{~mm}$ and $\mathrm{CL}-1=5.067$.

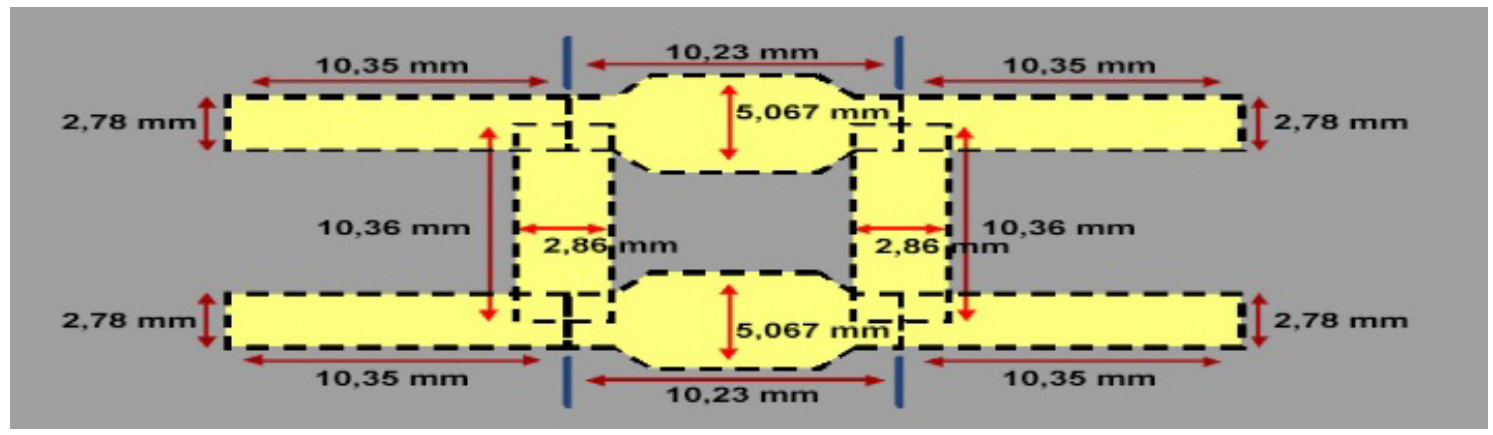

Figure 4. Optimal dimension of Coupler

In the picture above shows the dimensions of the coupler optimization results.

A. Simulation Result

Simulations carried out after the calculation and optimization. The result is shown in Figure 5. 


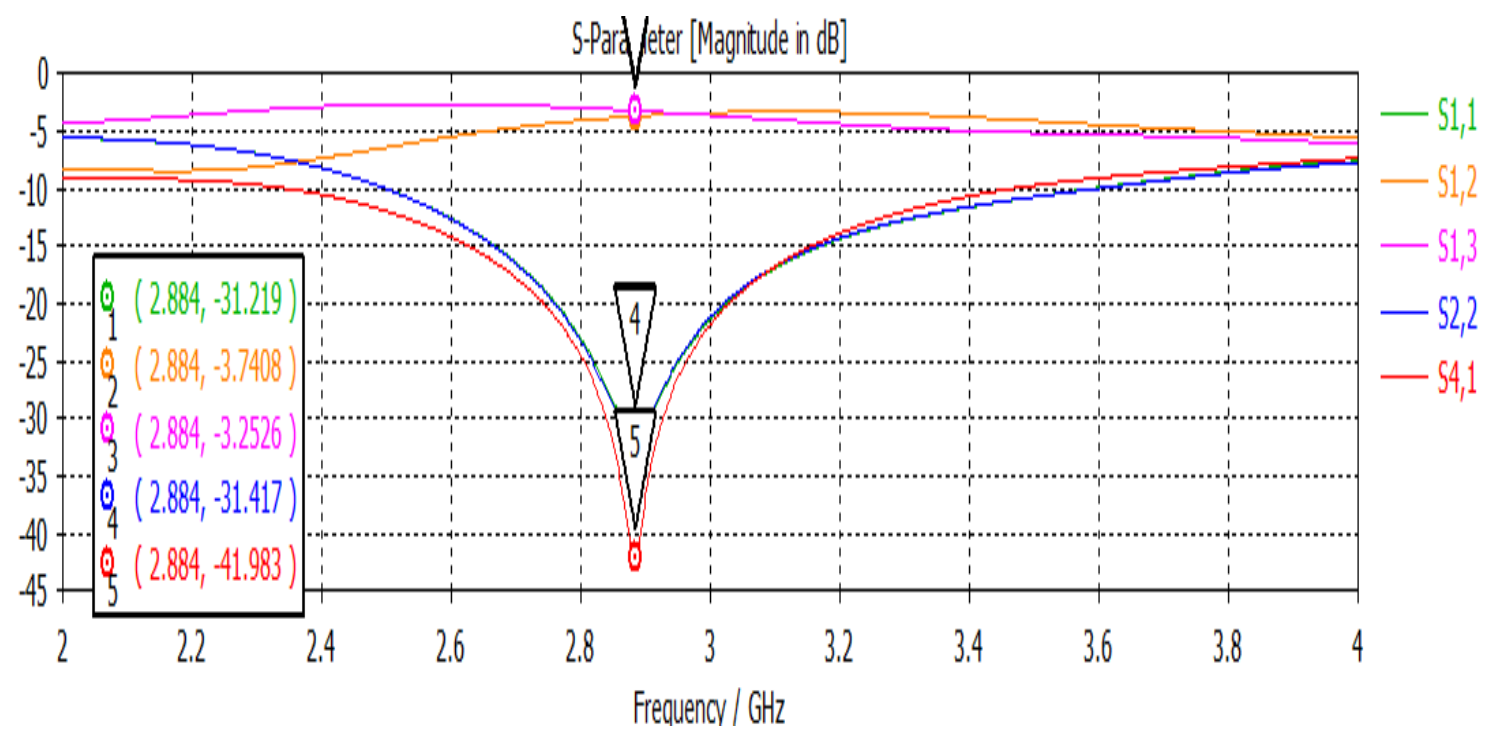

Figure 5. Simulation result from calculation

It can be seen at Figure 5, that the operation frequency is shifted to $2.884 \mathrm{GHz}$ instead of $3 \mathrm{GHz}$. After optimization is conducted, the result is shown in Figure 6.

From the figure 7 , The isolation obtained reach $-67.786 \mathrm{~dB}$. This is the best value of isolation.

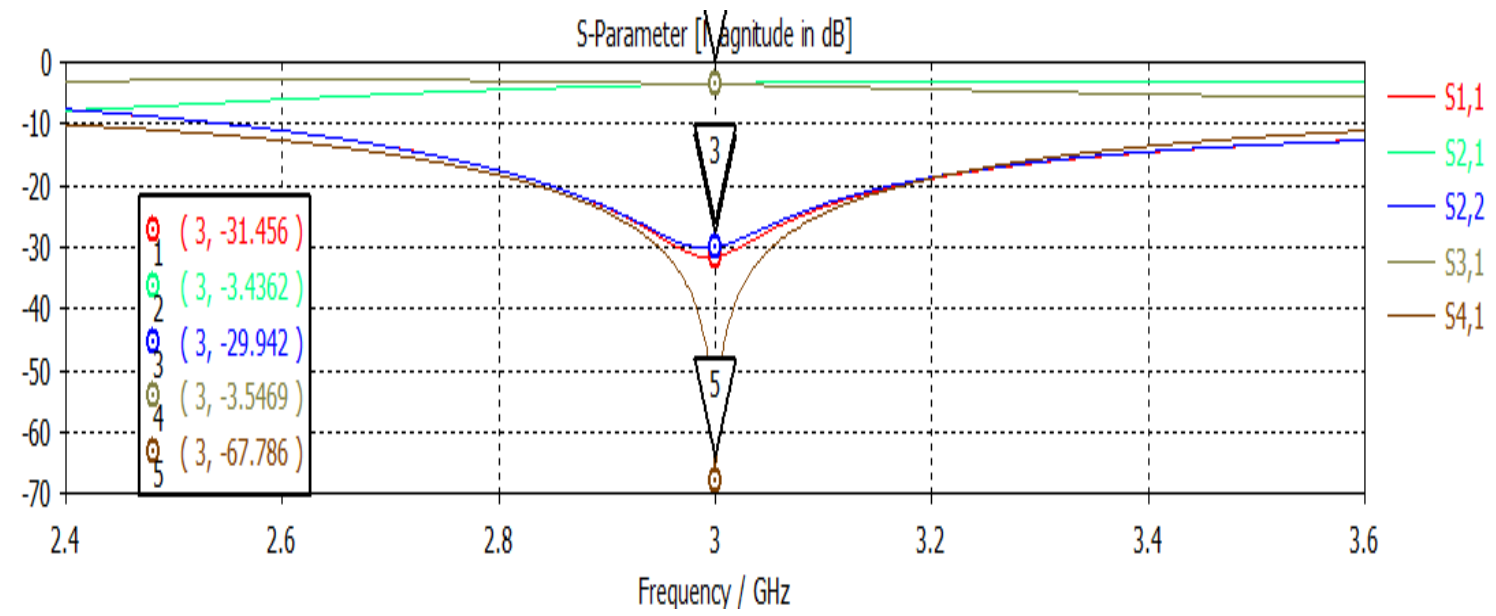

Figure 6. Simulation result s parameter from optimal dimension

B. Comparison dimension calculation and optimization result

The comparison of the dimension of the best isolation BLC with the conventional one can be seen at Table 5 .

Tabel 5. Comparison dimensions calculation result and optimization

\begin{tabular}{|c|c|c|}
\hline Variable & $\begin{array}{c}\text { Dimension } \\
\text { Calculation }(\mathrm{mm})\end{array}$ & $\begin{array}{c}\text { Optimization } \\
\text { Dimension }(\mathrm{mm})\end{array}$ \\
\hline $\mathrm{AP}$ & 11.66 & 10.35 \\
\hline $\mathrm{A}: \mathrm{L}$ & 2.398 & 2.78 \\
\hline $\mathrm{BP}$ & 11.66 & 10.36 \\
\hline $\mathrm{BL}$ & 2.398 & 2.86 \\
\hline $\mathrm{CP}$ & 11.66 & 10.23 \\
\hline $\mathrm{CL}$ & 4.125 & 5.067 \\
\hline
\end{tabular}

\section{Conclusions}

The values of the parameter $\mathrm{S}$ in the simulation results of return loss (S11) on the coupler is $-31.456 \mathrm{~dB}$ while the measurement result is $-29.032 \mathrm{~dB}$ [13]. The isolation value of the measurement result is $-64.546 \mathrm{~dB}$ and the simulation result is $-67.786 \mathrm{~dB}$, phase measurement results obtained $-91.66 \circ$ for $\mathrm{S} 13$ and $\mathrm{S} 31$. This is close to the ideal value is $90^{\circ}$. VSWR simulation results obtained are vswr $1=$ vswr 4 $=1.055$ and vswr $2=v s w r 3=1.0658$ and they are close to the ideal value, the coupling factor of the simulation (S13) is $-3.546 \mathrm{~dB}$ at a frequency of $3 \mathrm{GHz}$ and the measurement result is $-3.565 \mathrm{~dB}$ of results. So that, the results can be concluded that the Coupler can be implemented as a duplexer. 


\section{REFERENCES}

[1] W-d, Wirth. Radar Techniques Using Array Antennas. IEE, 2001

[2] Vijiyan, G. (2015). Current Trends in Software Engineering Research. Abstract of Emerging Trends in Scientific Research, 3, 1-12.

[3] Byung-Jun Ahn, S.K Kim and J.G Yook, "Isolation-Improved Coupler Based

[4] On Feed-forward Technique" , Dept of Electrical and Electronic Eng. Yonsei Univ. Korea, IEEE 2005

[5] M. Moradian and M. Khalaj-Amirhosseini, "Improvement the Characteristic Of the Microstrip Parallel Couple line Coupler by means of Grooved Substrate", Dept of Electrical Engineering Iran University of Science and Technology Narmak, M, Vol. 3, 205-215, 2008

[6] M. Moradian, "Improving isolation of slot-coupled directional couplers," Electronic Letters 11th, vol.51 No.12,pp 914-915, June 2015

[7] Wilems,D. A, “ A boadband MMIC-S quadrature coupler using a braided microstrip structure", IEEE MTT-S International, Microwave Symposium Digest, vol. 2, pp 899-902, May 1994

[8] S. Banda and H. Ogawa, " Multilayer MMIC directional couple using thin dielectric layers," IEEE Trans. Microwave Theory and Tech, vol.43, pp 1270-1275, June 1995

[9] Carchon, G, De Raedt, W. And Nauwelaers, B, "Integration of CPW Quadrature Couplers in Multilayer thin-film MCM-D”, IEEE Trans. Micro-wave Theory and Tech, vol.49,pp 1770-1776, Oct 2001

[10] Kumar, B. S., \& Cristin, R. (2018). A Survey on Efficient Power Management Using Smart Socket and IoT. Review of Computer Engineering Research, 5(2), 25-30.

[11] Lukas W. Mayer, Arpad L. Scholtz, "Circularly Polarized Patch Antenna with High Tx-Rx separation", Vienna Univ of Technology, IEEE. 2009

[12] Riyanti Indah, "Perancangan Microstrip Branch - line Coupler dengan T- Junction untuk Mobile Wimax pada Frekuensi 2, 3 GHz." Skripsi S1 Universitas Indonesia, 2009.

[13] M. Moradian, “ Improving isolation of slot-coupled directional couplers," Electronic Letters 11th, vol.51 No.12,pp 914-915, June 2015

[14] Jabarullah, N. H., Verrelli, E., Gee, A., Mauldin, C., Navarro, L. A., Golden, J. H., \& Kemp, N. T. (2016). Large dopant dependence of the current limiting properties of intrinsic conducting polymer surge protection devices. RSC Advances, 6(89), 85710-85717. 